\title{
Ginkgo biloba Exocarp Extract Inhibits the Metastasis of B16-F10 Melanoma Involving PI3K/Akt/NF- $\kappa$ B/MMP-9 Signaling Pathway
}

\author{
Chenjie Cao, ${ }^{1}$ Ya Su, ${ }^{1}$ Yanqi Gao, ${ }^{1}$ Chengrong Luo, ${ }^{1}$ Lu Yin, ${ }^{1}$ \\ Yingjie Zhao, ${ }^{1}$ Huasheng Chen, ${ }^{2}$ and Aihua $\mathrm{Xu} \mathbb{D}^{1,3}$ \\ ${ }^{1}$ Department of Pharmacology, Medical College of Yangzhou University, Yangzhou, Jiangsu Province 225001, China \\ ${ }^{2}$ Department of Combination of Traditional Chinese and Western Medicine, Medical College of Yangzhou University, \\ Yangzhou, Jiangsu Province 225001, China \\ ${ }^{3}$ Jiangsu Co-Innovation Center for Prevention and Control of Important Animal Infectious Diseases and Zoonoses, Yangzhou, \\ Jiangsu Province 225001, China
}

Correspondence should be addressed to Aihua Xu; ahxu@yzu.edu.cn

Received 18 January 2018; Revised 30 April 2018; Accepted 15 May 2018; Published 25 June 2018

Academic Editor: Kuzhuvelil B. Harikumar

Copyright (C) 2018 Chenjie Cao et al. This is an open access article distributed under the Creative Commons Attribution License, which permits unrestricted use, distribution, and reproduction in any medium, provided the original work is properly cited.

\begin{abstract}
In recent years, interest in natural plant extracts for cancer treatment is growing in the drug development field. Ginkgo biloba exocarp extract (GBEE) is known for possessing inhibitory effects on various mouse and human cancer cells. And no adverse reactions were observed during its clinical application to cancer patients. The aim of this study is to investigate the inhibitory effect of GBEE on the metastasis of B16-F10 melanoma and its related mechanisms. The B16-F10 melanoma lung metastasis model was established in C57BL/6J mice. It was found that GBEE inhibited the growth and pulmonary metastasis of B16-F10 melanoma transplanted tumor and downregulated the level of MMP-9 protein. Meanwhile, the B16-F10 cells were used to study in vitro. The results showed that GBEE inhibited the proliferation and migration of B16-F10 cells. Simultaneously, it suppressed the heterogeneous adhesion of B16-F10 cells to human umbilical vein endothelial cells (HUVEC) in a concentration-dependent manner. In addition, the levels of p-PI3K, p-Akt, NF- $\kappa \mathrm{B}$, and MMP-9 were decreased, while the PI3K and Akt were not significantly changed. These results indicate that GBEE can inhibit the metastasis of B16-F10 melanoma via multiple links and the molecular mechanism involved the regulation of PI3K/Akt/NF- $\kappa \mathrm{B} / \mathrm{MMP}-9$ signaling pathway.
\end{abstract}

\section{Introduction}

Malignant melanoma (MM) is a kind of cancer with high metastatic potential, which is formed by the malignant transformation of normal melanocytes [1]. It is one of the most rapidly growing malignancies in the world with an annual increase of $3 \%-5 \%$ [2].

At present, the clinical commonly used chemotherapy drugs such as dacarbazine and temozolomide have a certain therapeutic effect, but it often occurs that melanoma cells metastasize and spread during chemotherapy in patients, which is the main reason leading to the short survival and poor prognosis $[3,4]$. Therefore, the control of the metastasis of melanoma has become the key to the whole treatment [5].
In recent years, many studies have found that natural products have good therapeutic effects on cancer $[6,7]$, and some extracts of traditional Chinese medicine can inhibit the metastasis of malignancy $[8,9]$.

Ginkgo biloba L. is also known as Ginkgo nuts. It is a unique tree species in China, which is rare and ancient. Both the leaves and fruits have important medicinal value [10]. Ginkgo biloba exocarp is the succulent skin outside Ginkgo nuts. Ginkgo biloba exocarp extract (GBEE) is a mixture extracted from Ginkgo biloba exocarp using water solution-alcohol precipitation method according to the process of Chinese invention patent in our laboratory, taking proteoglycan as the main active ingredient [11]. In addition, 
it does not contain the harmful ingredient, ginkgolic acid [12]. Previous studies have shown that GBEE has inhibitory effects on various mouse and human cancer cells [13-15], and it can also promote the immune function of the body $[16,17]$. Meanwhile, no adverse reactions were observed during its clinical application to cancer patients. It has good application prospects $[18,19]$. Studies on GBEE inhibiting the metastasis of melanoma have not yet been involved. In this study, the B16-F10 melanoma cell line was selected. The inhibitory effect of GBEE on B16-F10 melanoma metastasis and its related mechanisms were explored in vivo and in vitro by establishing B16-F10 melanoma lung metastasis model in mice and culturing B16-F10 cells in vitro.

\section{Materials and Methods}

2.1. GBEE. Ginkgo nuts samples were obtained from Taixing (Jiangsu Province, China), identified by Meng Yin (Director of pharmacists) in Yangzhou Food and Drug Inspection and Testing Center (Jiangsu Province, China) as the family plant of Ginkgo biloba L. The succulent skin was peeled off by hand. The GBEE was prepared according to the invention patent method in our laboratory (Patent Number: CN 201010251050.9) [11]. The final concentration of ethanol was $80 \%$, and the precipitate was dried in vacuo. Then the offwhite powder was obtained and sealed at room temperature. The content of proteoglycan was $66.4 \%$, measured by phenolsulfuric acid method and brilliant blue method. Infrared Spectroscopy (IR) reported that the GBEE contained characteristic peak of polysaccharide. High Performance Liquid Chromatography (HPLC) and Thin Layer Chromatography (TLC) made the fact that the polysaccharide contained 7 kinds of monosaccharides including mannose, rhamnose, galacturonic acid, glucose, galactose, fructopyranose, and arabinose clear. The protein contained 14 kinds of amino acids including aspartic acid, glutamic acid, serine, glycine, threonine, alanine, proline, valine, methionine, isoleucine, leucine, phenylalanine, tryptophan, and lysine [20]. The voucher specimen of GBEE was deposited at the pharmacy experimental center in Medical College of Yangzhou University.

2.2. Chemicals and Reagents. Dulbecco's modified eagle medium (DMEM) and fetal bovine serum (FBS) were obtained from Gibco (Grand Island, NY, USA). Penicillin and streptomycin were purchased from Lukang Pharmaceutical (Shandong, People's Republic of China). cisDichlorodiammineplatinum (II) (DDP) was purchased from Jingkehongda Biotechnology (Beijing, People's Republic of China). 3-(4, 5-Dimethylthiazol-2-yl)-2, 5-diphenyl-tetrazolium bromide (MTT) was purchased from Sigma-Aldrich (St. Louis, MO, USA). Tris base, glycine, sodium dodecyl sulphate (SDS), Tween 20, Bovine Serum Albumin (BSA), and polyvinylidene fluoride (PVDF) membrane were obtained from Biosharp (Anhui, People's Republic of China). Sodium chloride $(\mathrm{NaCl})$, ethanol, methanol, and other chemical reagents were derived from Sinopharm Chemical Reagent (Beijing, People's Republic of China).
Immunohistochemistry kit, Radio-Immunoprecipitation Assay (RIPA) lysate, and 3,3'-diaminobenzidine (DAB) were obtained from Boster (Wuhan, People's Republic of China). Trizol, diethyl pyrocarbonate (DEPC), primers, M-MuLV First Strand cDNA Synthesis Kit, 2xSG Fast qPCR Master Mix, and secondary antibody consisting of horseradish peroxidase-conjugated IgG were purchased from BBI (Shanghai, People's Republic of China). BeyoECL Plus and Enhanced BCA Protein Assay Kit were purchased from Beyotime (Shanghai, People's Republic of China). NF- $\kappa \mathrm{B}$ rabbit anti-mouse antibody was obtained from Wanleibio (Shenyang, People's Republic of China). Phosphor-PI3K (p-PI3K), PI3K, phosphor-Akt (p-Akt), and Akt anti-mouse rabbit antibodies were purchased from Cell Signaling Technology (MA, USA). GAPDH and MMP-9 anti-mouse rabbit antibodies were obtained from Abcam (Cambridge, England).

2.3. Cell Culture. The human umbilical vein endothelial cell (HUVEC) line and B16-F10 cell line were purchased from Shanghai cell bank, Chinese Academy of Sciences. The cells were cultured in DMEM with $10 \%$ FBS, $100 \mathrm{U} / \mathrm{mL}$ penicillin, and $100 \mathrm{~g} / \mathrm{ml}$ streptomycin. The cells were incubated in a humidified incubator at $37^{\circ} \mathrm{C}$ with $5 \% \mathrm{CO}_{2}(\mathrm{v} / \mathrm{v})$ and subcultured according to trypsin digestion method. The passage time was usually 3 days.

2.4. Animals. The $\mathrm{C}_{57} \mathrm{BL} / 6 \mathrm{~J}$ mice were provided by the Center of Comparative Medicine of Yangzhou University. The mice (SPF class) were female and 6 weeks old, weighing 1822 g. Animal Certificate was SCXK Su 2012-0004; animal use license was SYXK Su 2012-0029. They had been acclimated on $12 \mathrm{~h}$ light/12 $\mathrm{h}$ dark cycle for one week before use. All the animal studies were conducted in conformity with the Institutional Animal Ethics Committee of Yangzhou University and the National Institutes of Health Guide for Care and Use of Laboratory Animals.

\subsection{Detection of the Tumor Inhibition Rate and Antipulmonary} Metastasis Rate. The B16-F10 cells were diluted by normal saline, and the cell suspension $\left(1.0 \times 10^{7}\right.$ cells $\left./ \mathrm{mL}\right)$ was prepared. A volume of $0.2 \mathrm{~mL}$ of such B16-F10 cell suspension was inoculated subcutaneously in the right forelimb armpit of the mice. Once the transplanted tumor grew to appropriate size, the tumor tissue was removed and cut. The tumor cell suspension was prepared according to the conventional methods. The density was adjusted to $1.0 \times 10^{7}$ cells $/ \mathrm{mL}$ and the cell suspension was inoculated subcutaneously in the right forelimb armpit of the mice. Each mouse was injected with a volume of $0.2 \mathrm{~mL}$ tumor cell suspension. $24 \mathrm{~h}$ after inoculating, the mice were randomly divided into 6 groups, and there were ten mice in each group. Groups and dose: the normal control group (NCG, without tumor cells) and the model control group (MCG) were given normal saline [0.1 $\mathrm{mL} / 10 \mathrm{~g}$ (body weight)] by intragastric gavage (ig), once a day for 17 days; the mice in positive control group (PCG) were given DDP [ $5 \mathrm{mg} / \mathrm{kg}$ (body weight)] by intraperitoneal (ip), every other day for 7 days; the GBEE groups were given GBEE 
[50,100, $200 \mathrm{mg} / \mathrm{kg}$ (body weight)] by ig, once a day for 17 days. On the 18th day, the mice were sacrificed by cervical dislocation and the transplanted solid tumor was completely stripped and weighed. The tumor inhibition rate $=$ (average tumor weight in MCG - average tumor weight in treated groups)/average tumor weight in MCG $\times 100 \%$.

The lung tissue were removed and fixed. The number of lung metastasis foci was counted and the diameter was gauged, using anatomical microscope (Nikon, Tokyo, Japan). The number of metastasis foci $=\mathrm{I} \times 1+\mathrm{II} \times 2+\mathrm{III} \times 3+\mathrm{IV} \times 4$ (according to the diameter, the foci are divided into four levels: Level I $<0.5 \mathrm{~mm}, 0.5 \mathrm{~mm} \leq$ Level II $<1 \mathrm{~mm}, 1 \mathrm{~mm} \leq$ Level III $\leq 2 \mathrm{~mm}$, Level IV $>2 \mathrm{~mm}$ ). The antimetastatic rate $(\%)=$ (average number of lung metastasis foci in MCG - average number of lung metastasis foci in treated groups)/average number of lung metastasis foci in MCG $\times$ $100 \%$.

2.6. Hematoxylin-Eosin (HE) Staining Assay. The lung tissues were fixed in $10 \%$ neutral formalin for $24 \mathrm{~h}$, then dehydrated with ethanol, and transparent with xylene. They were embedded in paraffin and cut into slices. The dried slices were transparent with xylene for 5-10 min and then moved into the hematoxylin to soak and stain for 1-2 min. Then they were differentiated in $1 \%$ hydrochloric acid alcohol and stained using eosin for 2-5 min. Finally, the slices were dehydrated with alcohol, transparent with xylene, and sealed in resin. Then the pathological slices of lung tissue were observed using optical microscope (Nikon, Tokyo, Japan). The B16F10 cells are characterized by large nuclei, deep staining, and marked atypia; simultaneously, they accumulated as clumps whose shape and distribution were irregular.

2.7. Immunohistochemistry Assay. The transplanted tumor tissues were fixed in $10 \%$ neutral formalin for $24 \mathrm{~h}$ and then dehydrated with ethanol and transparent with xylene. They were embedded in paraffin and cut into slices. The dried slices were transparent with xylene and dehydrated with gradient of ethanol. The activity of endogenous peroxidase on sections was blocked with $3 \% \mathrm{H}_{2} \mathrm{O}_{2}$. The antigens were repaired with microwave ovens. In order to reduce nonspecific reactions, the slices were blocked by $5 \%$ BSA before incubated with MMP-9 antibody overnight. Then the slices were incubated with horseradish peroxidase-conjugated Goat Anti-Rabbit IgG and stained with $\mathrm{DAB}$ and $\mathrm{SABC}$. The slices were finally counterstained with hematoxylin. Phosphate buffer saline (PBS) was used to wash the slices after each step and replace the primary antibody as a negative control. The results of the target protein were obtained under optical microscope (Nikon, Tokyo, Japan). The expression of MMP-9 protein was located in the cytoplasm and the positive staining showed brown. Each slice was randomly selected five fields in the high magnification, and the mean integrated optical density (IOD) of MMP-9 positive chromatin was determined using image analysis software Image-pro Plus 6.0.

2.8. MTT Assay. The B16-F10 cells in logarithmic growth phase $\left(2 \times 10^{5}\right.$ cells $\left./ \mathrm{mL}\right)$ were seeded in 96 -well plate. After cell attachment, the treated groups were given DMEM medium containing GBEE, and the final concentrations of GBEE were $5,10,20,40,80,160$, and $320 \mu \mathrm{g} / \mathrm{mL}$. The cells in PCG were treated with DDP $(5 \mu \mathrm{g} / \mathrm{mL})$ and the cells in blank control group were treated with equal volume of DMEM medium. MTT solution $(5 \mathrm{mg} / \mathrm{mL})$ was added after the cells were cultured in a humidified atmosphere of $5 \% \mathrm{CO}_{2}$ at $37^{\circ} \mathrm{C}$ for $44 \mathrm{~h}$. Subsequently, the cells were incubated for $4 \mathrm{~h}$. Then the culture medium was discarded and the acidified isopropanol was added. After the blue purple crystal fully dissolved, the optical density (OD) was measured using a microplate reader (MULTISKAN FC, Thermo, MA, USA) at $570 \mathrm{~nm}$. Finally, the inhibition rate was calculated pursuant to the following formula: the inhibition rate $=\left(1-\mathrm{OD}_{\text {treated groups }} /\right.$ $\left.\mathrm{OD}_{\text {blank control group }}\right) \times 100 \%$.

2.9. Wound Healing Assay. The B16-F10 cells in logarithmic growth phase were digested by $0.25 \%$ pancreatin and were evenly placed on 6 -well plate $\left(1 \times 10^{6}\right.$ cells $\left./ \mathrm{mL}\right)$. After the cells were grown to $90 \%$ confluence, the center of each cell monolayer was scraped with a sterile $200 \mu \mathrm{L}$ tip pipette as to create a denuded zone. The DMEM medium was discarded, and each well was washed twice. Then the cells were treated with GBEE $(10,20$, and $40 \mu \mathrm{g} / \mathrm{mL})$ and DDP for $48 \mathrm{~h}$. During this period, the changes in the migration of the cells were observed and photographed using inverted microscope (Nikon, Tokyo, Japan) every $12 \mathrm{~h}$. The area and height of the wound were examined using Image-pro Plus 6.0. The area divided by the height gives the average width of the wound. Cell migration rate $=($ the average width at $0 \mathrm{~h}-$ the average width at $12,24,36$ or $48 \mathrm{~h}$ ) / the average width at $0 \mathrm{~h}$ ) $\times 100 \%$.

2.10. Cell Adhesion Assay. The HUVEC were the target cells in this assay, and the B16-F10 cells were the tested cells. The B16-F10 cells $\left(2 \times 10^{5} / \mathrm{mL}\right)$ in logarithmic growth phase were inoculated into the culture flasks. After $12 \mathrm{~h}$ of cultivation, $\operatorname{GBEE}(10,20,40 \mu \mathrm{g} / \mathrm{mL})$ and DDP were added $(1 \mathrm{~mL} /$ culture flask). And the cells in blank control group were treated with equal volume of DMEM medium. They were all treated for 24 h.

The HUVEC were seeded in 96 -well plate $(100 \mu \mathrm{L} /$ well $)$ at a density of $2 \times 10^{5}$ cells $/ \mathrm{mL}$ and then cultured for $12 \mathrm{~h}$. When the target cells grew to confluence, the B16-F10 cells that have been treated for $24 \mathrm{~h}$ were collected and seeded into the target cells at a density of $2 \times 10^{5}$ cells $/ \mathrm{mL}(100 \mu \mathrm{L} /$ well). Subsequently, the two kinds of cells were cocultured for 2 $\mathrm{h}$, making the tested cells fully adhered to the target cells. After the cultivation was completed, the nonadherent cells were removed. MTT method was applied to detect the OD value. The cell adhesion inhibition rate $=\left(1-\mathrm{OD}_{\text {treated groups }} /\right.$ $\left.\mathrm{OD}_{\text {blank control group }}\right) \times 100 \%$.

2.11. $q R T$-PCR Assay. The B16-F10 cells $\left(2 \times 10^{5}\right.$ cells $\left./ \mathrm{mL}\right)$ in logarithmic growth phase were seeded in 6-well plate. GBEE $(10,20,40 \mu \mathrm{g} / \mathrm{mL})$ and DDP were added after cell adherence, and the blank control group were established. The total RNA was extracted with Trizol (300 $\mu \mathrm{L} /$ well) after the cells were treated for $48 \mathrm{~h}$. The RNA was reverse transcribed into cDNA 
TABLE 1: List of qRT-PCR primers.

\begin{tabular}{lrc}
\hline Gene & Forward primer & Reverse primer \\
\hline PI3K & $5^{\prime}$-AACTCTGGGGATGACCTGGA-3' & $5^{\prime}$-AGGCGGTCACAACACTCCTA-3 \\
Akt & $5^{\prime}$-AGGGTTGGCTGCACCGCG-3 \\
NF- $\kappa$ B & $5^{\prime}$-AGTTGAGGGGACTTTCCCAGGC-3' & $5^{\prime}$-GTTGTTGAAGAGACACCGCG-3' \\
MMP-9 & $5^{\prime}$-AGACCAAGGGTACAGCCTGTTC-3' & $5^{\prime}$-TCAACTCCCCTGAAAGGGTCCG-3' \\
GAPDH & $5^{\prime}$-ACACCCACTCCTCCACCTTT-3' & $5^{\prime}$-GGCACGCTGGAATGATCTAAG-3' \\
\hline
\end{tabular}

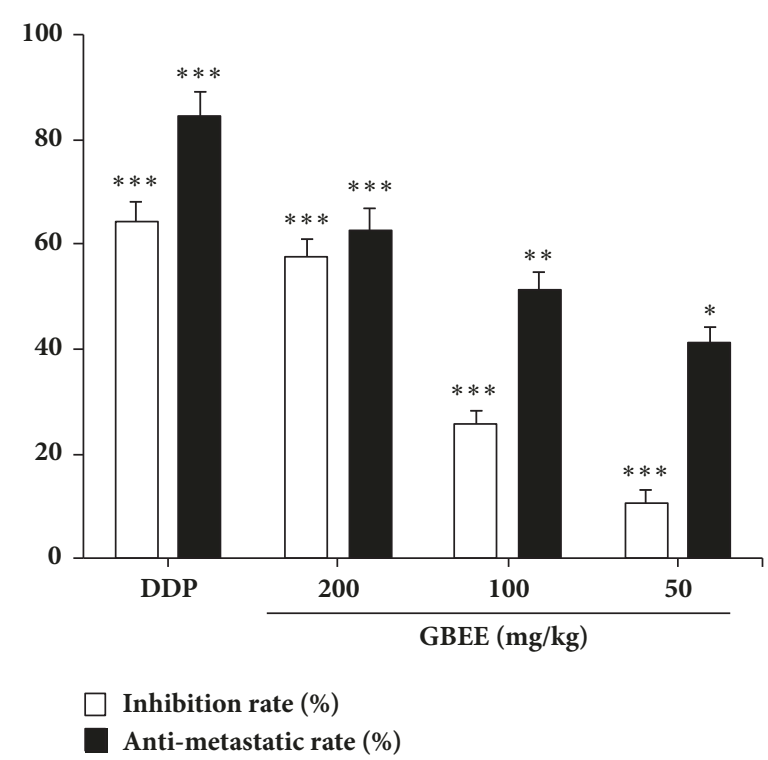

FIGURE 1: GBEE inhibited the growth and pulmonary metastasis of B16-F10 melanoma transplanted tumor. Mice with transplantation tumor were treated with NS, DDP, and GBEE $(50,100$, and $200 \mathrm{mg} / \mathrm{kg})$. After giving corresponding drugs for 17 days, the tumor blocks and lung tissues were stripped, and the inhibition rate and antimetastatic rate were calculated. Data are shown as mean $\pm \mathrm{SD}(n=10)$. ${ }^{*} P<0.05$, ${ }^{* *} P<0.01$, and ${ }^{* * *} P<0.001$ versus model.

using M-MuLV First Strand cDNA Synthesis Kit. Then the cDNA was amplified with 2xSG Fast qPCR Master Mix using PCR instrument (Roche Light Cycler 96, Basel, Switzerland). GAPDH was the reference gene. The sequences of primers are shown in Table 1. Each sample was repeated three times and calculated the average cycle threshold (Ct). The real-time fluorescence quantitative was analyzed by $2^{-\Delta \Delta C t}$ method, and the value of RQ (relative quantification) was calculated.

2.12. Western Blot Assay. The B16-F10 cells $\left(2 \times 10^{5}\right.$ cells $\left./ \mathrm{mL}\right)$ in logarithmic growth phase were seeded in 6 -well plate. The cells were treated in the same way as that in "Section 2.11". The total protein was extracted after the cells were treated for $48 \mathrm{~h}$, and the concentration was determined by BCA assay. The total protein was separated by SDS polyacrylamide gel electrophoresis and then transferred to PVDF membrane. 5\% BSA was used to seal the membrane at room temperature for $1.5 \mathrm{~h}$. The membrane was incubated with the primary antibody overnight at $4^{\circ} \mathrm{C}$ and the secondary antibodies conjugated to horseradish peroxidase were added. After $4 \mathrm{~h}$, the fluorescent substrate was prepared and the results were recorded in gel imaging system (BIO-RAD, Hercules, CA, USA). The analyzing software (Image J) was used to analyze the gray value. The relative levels of target proteins were obtained, taking GAPDH as the internal reference.

2.13. Statistical Analysis. All data in this experiment were analyzed using SPSS 17.0 (SPSS Inc., Chicago, IL, USA) and presented as mean \pm standard deviation (SD). The groups were compared using $\mathrm{F}$ test and Dunnett's t-test. $P<0.05$ was considered to be significantly different.

\section{Results}

3.1. GBEE Inhibited the Growth and Metastasis of B16F10 Melanoma Transplanted Tumor. GBEE (50, 100 and $200 \mathrm{mg} / \mathrm{kg}$ ) had a significant inhibitory effect on the growth of B16-F10 transplanted tumor with a dose-effect relationship. Simultaneously, the antipulmonary metastasis rate was increased with the increase of dose, appearing a significant antimetastasis effect (Figure 1).

3.2. Pathological Observation of Lung Metastasis Foci. HE staining revealed that the number and area of lung metastases foci were both significantly reduced in all $\operatorname{GBEE}(50,100$, and $200 \mathrm{mg} / \mathrm{kg}$ ) treated groups compared with the model 


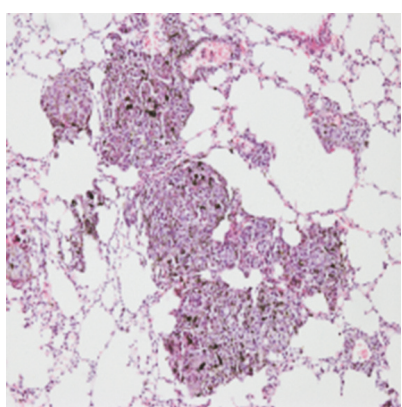

(a)

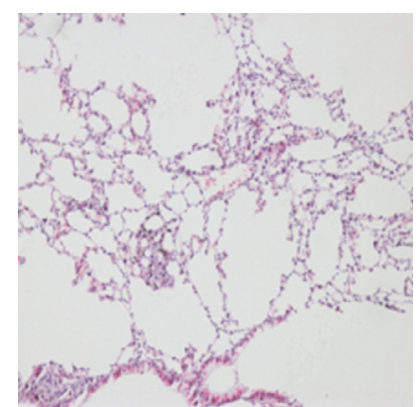

(b)

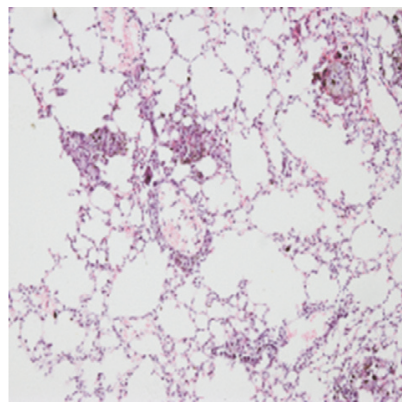

(c)

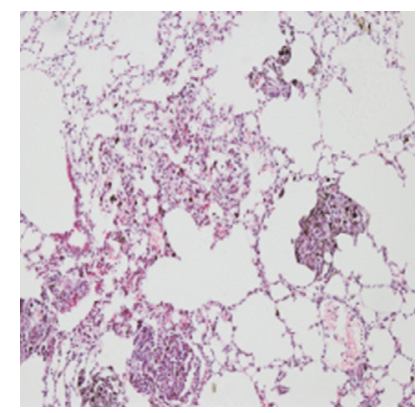

(d)

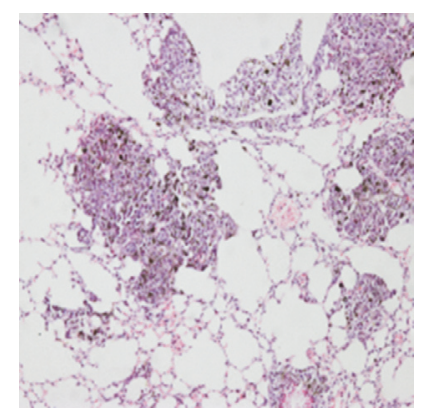

(e)

Figure 2: Histological examination of lung tissue and antimetastatic rate in different groups. Mice with transplantation tumor were treated with (a) NS, (b) DDP, GBEE (c) $200 \mathrm{mg} / \mathrm{kg}$, (d) $100 \mathrm{mg} / \mathrm{kg}$, and (e) $50 \mathrm{mg} / \mathrm{kg}$. After giving corresponding drugs for $17 \mathrm{days}$, HE staining analysis was carried out. The nucleus of cancer cells in metastasis foci was dyed blue and the cytoplasm was dyed red (100×).

group, and the effect of high dose group was more obvious (Figure 2).

3.3. GBEE Inhibited the Level of MMP-9 Protein in Transplanted Tumor. Compared with the model group, the protein levels of MMP-9 in transplanted tumor were decreased with a dose-effect relationship in the $\operatorname{GBEE}(50,100$, and $200 \mathrm{mg} / \mathrm{kg})$ groups (Figure 3).

3.4. GBEE Inhibited the Proliferation of B16-F10 Cells In Vitro. The results of MTT assay showed that after GBEE (5-320 $\mu \mathrm{g} / \mathrm{mL}$ ) treated the B16-F10 cells for $48 \mathrm{~h}$, the proliferation of the cells was inhibited in a concentration-dependent manner. The half maximal inhibitory concentration (IC50) value was $94.0 \mu \mathrm{g} / \mathrm{mL}$ (Figure 4).

3.5. GBEE Inhibited the Migration of B16-F10 Cells. Wound healing assay explained that the cells in each group had no significant difference at $0 \mathrm{~h}$. After culturing for $48 \mathrm{~h}$, the wound in control group was almost fully healed, whereas the speed of wound healing in GBEE $(10,20$, and $40 \mu \mathrm{g} / \mathrm{mL})$ treated groups was significantly slowed down. Furthermore, compared with the control group, the inhibitory effect of GBEE on the migration of B16-F10 cells was dose-dependent as well as time-dependent (Figure 5).

3.6. GBEE Inhibited the Adhesion of B16-F10 Cells to HUVEC. As shown in Figure 6, GBEE $(10,20$, and $40 \mu \mathrm{g} / \mathrm{mL})$ significantly inhibited the heterogeneous adhesion of B16-F10 cells to HUVEC. The inhibitory effects were gradually increased as the concentration of GBEE increased.

3.7. GBEE Inhibited PI3K/Akt/NF- $\mathrm{B} / \mathrm{MMP}-9$ Signaling Pathway in B16-F10 Cells. qRT-PCR results showed that GBEE $(10,20$, and $40 \mu \mathrm{g} / \mathrm{mL})$ downregulated the mRNA levels of NF- $\kappa$ B and MMP-9 in a concentration-dependent manner and had no significant effect on the mRNA level of PI3K and Akt (Figure 7(a)).

Western Blot results explained that GBEE suppressed the protein levels of $\mathrm{p}-\mathrm{PI} 3 \mathrm{~K}, \mathrm{p}-\mathrm{Akt}, \mathrm{NF}-\kappa \mathrm{B}$, and MMP-9 in B16F10 cells in a concentration-dependent manner and had no significant effect on the PI3K and Akt protein (Figure 7(b)).

\section{Discussion}

For the first time, the study found that GBEE (50-200 mg/kg) could inhibit the growth of B16-F10 melanoma transplanted tumor and had an antipulmonary metastatic effect. HE staining showed that GBEE significantly reduced the number and area of lung metastases foci. These suggested that GBEE has an inhibitory effect on the metastasis of B16-F10 melanoma. Based on this, further research was conducted in this paper.

Tumor metastasis is a dynamic, continuous, and complex process. After the occurrence of malignant tumor, the overproliferation of primary tumor cells accelerates the growth of tumor tissue, which in turn causes the internal pressure of tumor tissues to rise, so that the tumor cells can 


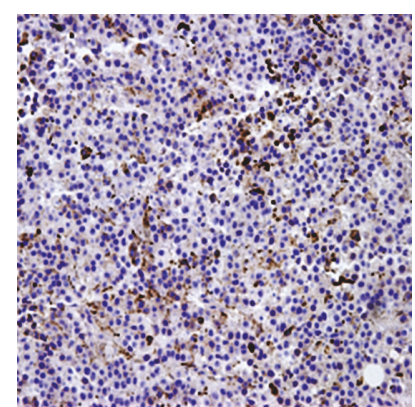

(a)

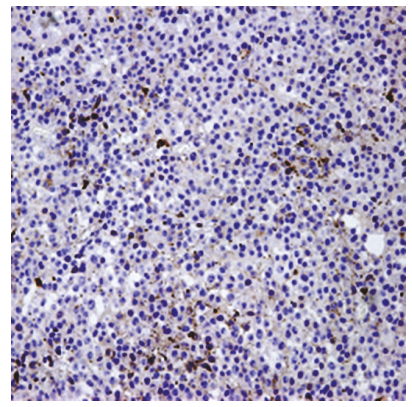

(d)

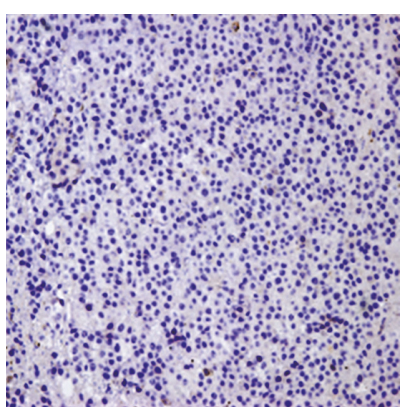

(b)

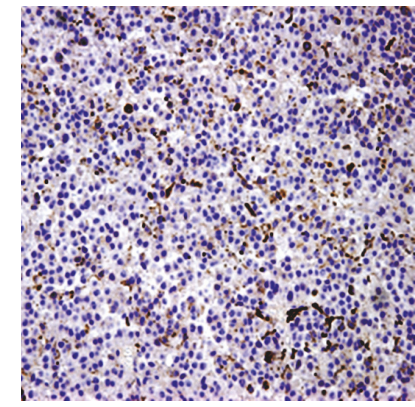

(e)

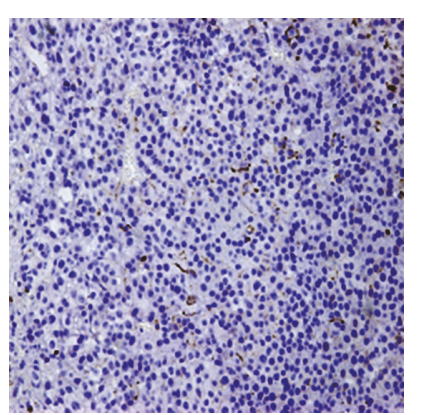

(c)

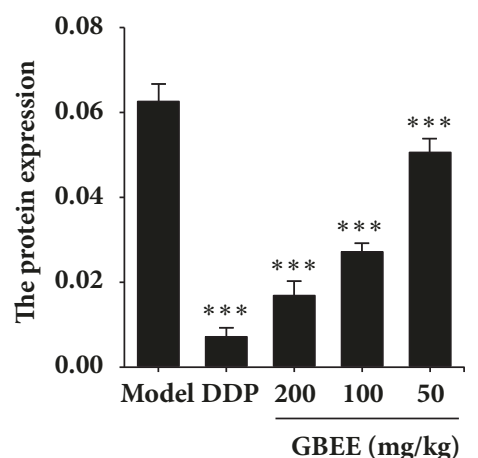

FIGURE 3: GBEE inhibited the level of MMP-9 protein in transplanted tumor. Mice with transplantation tumor were treated with (a) NS, (b) DDP, GBEE (c) $200 \mathrm{mg} / \mathrm{kg}$, (d) $100 \mathrm{mg} / \mathrm{kg}$, and (e) $50 \mathrm{mg} / \mathrm{kg}$. After giving corresponding drugs for 17 days, the immunohistochemistry analysis was carried out $(200 \times)$. The average IOD of positive staining of MMP-9 was measured by Image-pro Plus 6.0 software. Data are shown as mean $\pm \mathrm{SD}(n=3) .{ }^{* * *} P<0.001$ versus model.

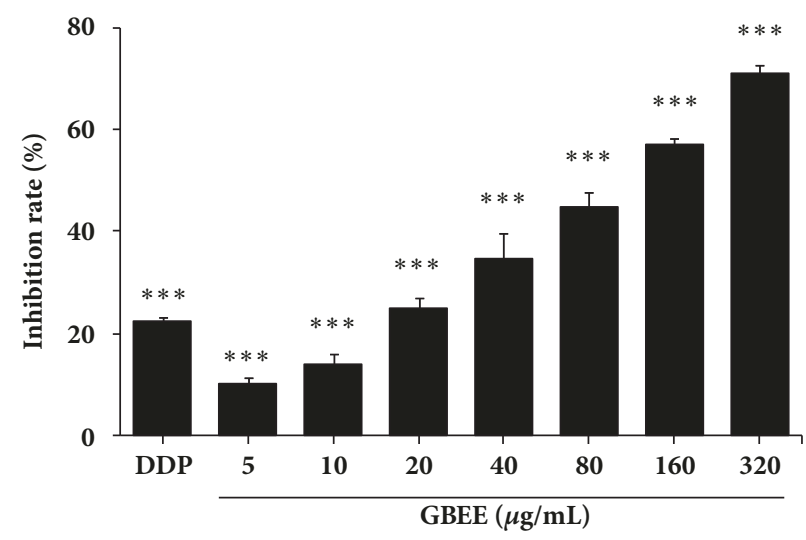

FIGURE 4: GBEE inhibited the proliferation of B16-F10 cells in vitro. The B16-F10 cells were treated with DDP and GBEE for 48 h. MTT assay was carried out. Data are shown as mean $\pm \mathrm{SD}(n=6) .{ }^{* * *} \mathrm{P}<0.001$ versus control.

be separated from the primary tumor foci. After that, the tumor cells invade the basement membrane (BM), and by means of secreting the related factors, the protein of BM is cracking and the gaps are formed, and then the tumor cells can move through the extracellular matrix (ECM) via the gap. Afterwards, the tumor cells adhere to the endothelial cells of the local capillaries or lymphatic capillaries and penetrate the wall, so that the tumor cells can reach the tissues and organs of the whole body with blood or lymph and continue to proliferate and form metastasis foci [21, 22]. Thus, the tumor cell proliferation, migration, heterogeneous adhesion, and the degradation of ECM and BM are all the key steps in tumor metastasis. MMP-9 is a kind of matrix metalloproteinases (MMPs). It has increased expression and activity in metastatic tumors and can specifically degrade ECM and BM $[23,24]$. The results of immunocytochemistry showed that GBEE (50-200 mg/kg) significantly reduced the expression of MMP-9 protein with a dose-effect relationship 
oh
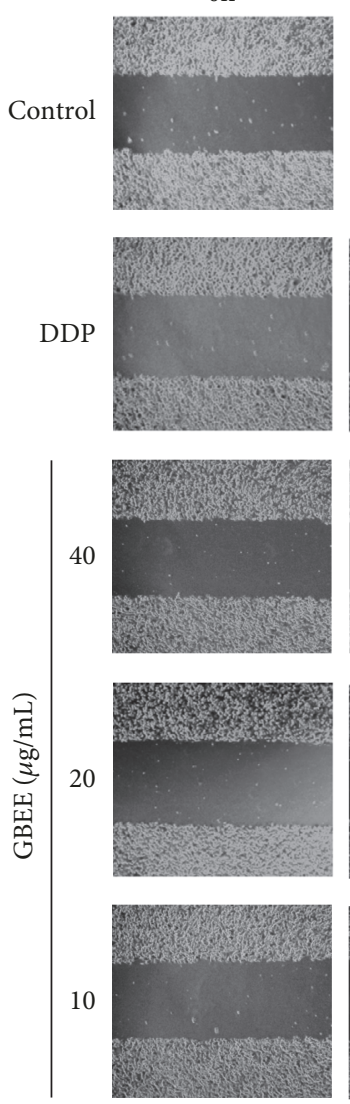

$12 \mathrm{~h}$
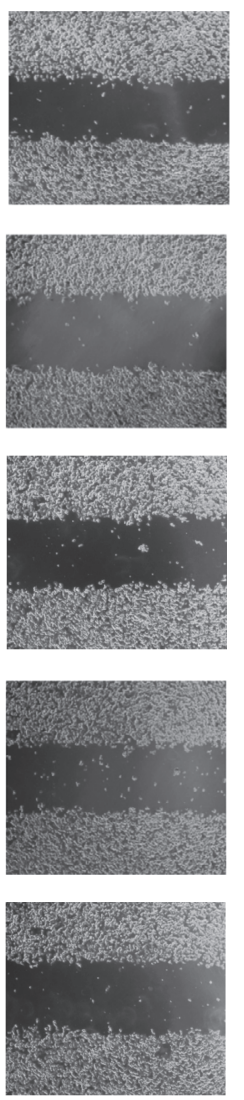

$24 \mathrm{~h}$
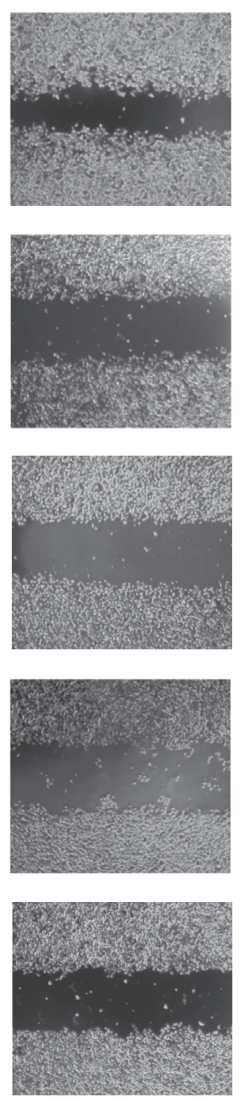

$36 \mathrm{~h}$
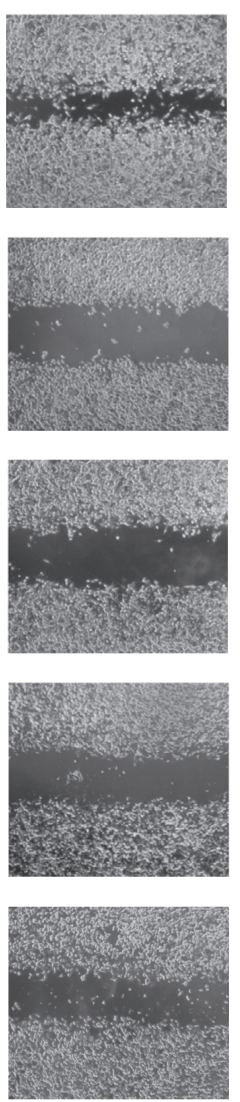

$48 \mathrm{~h}$
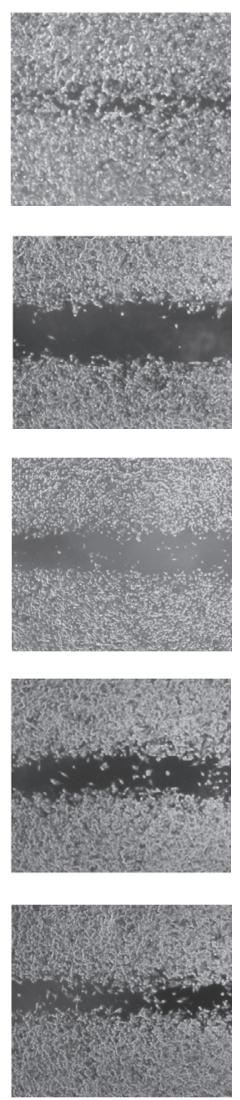

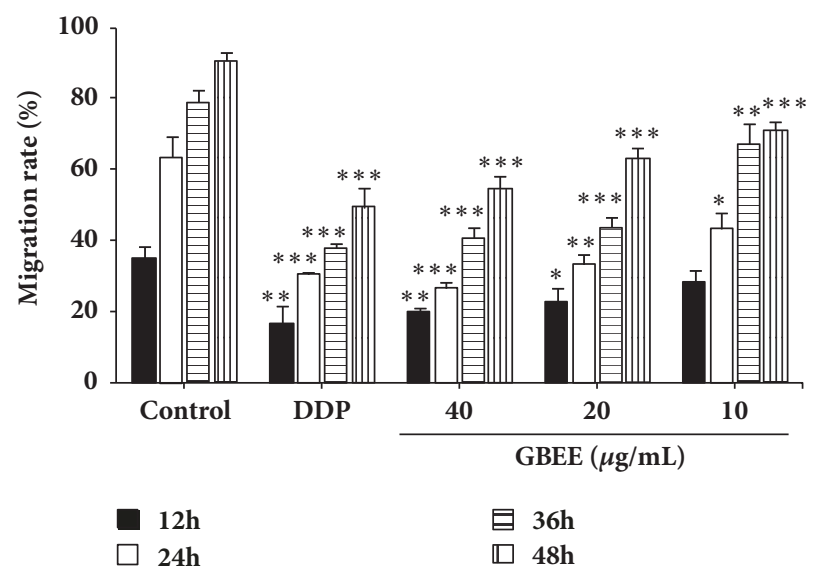

FIGURE 5: GBEE inhibited the migration of B16-F10 cells. The B16-F10 cells were treated with blank DMEM, DDP, and GBEE (10, 20, and $40 \mu \mathrm{g} / \mathrm{mL}$ ) for $48 \mathrm{~h}$. The migration of cells was observed. The cell mobility was measured by Image-pro Plus 6.0 software. Data are shown as mean $\pm \mathrm{SD}(n=3) .{ }^{*} P<0.05,{ }^{* *} P<0.01$, and ${ }^{* * *} P<0.001$ versus control.

in the transplanted tumor. The in vitro results showed that GBEE $(5-320 \mu \mathrm{g} / \mathrm{mL})$ inhibited the proliferation of B16-F10 melanoma cells in a concentration-dependent manner. GBEE also had inhibitory effects on the migration of B16-F10 cells and the heterogeneous adhesion of B16-F10 to HUVEC in a concentration-dependent manner at the concentration of $10-40 \mu \mathrm{g} / \mathrm{mL}$. These results suggested that the antimetastasis effect of GBEE on B16-F10 melanoma is related to its inhibition of tumor cell proliferation, migration, heterogeneous adhesion, and ECM and BM degradation.

$\mathrm{NF}-\kappa \mathrm{B}$ is an important nuclear transcription factor that participates in regulating metastasis and many other actions of tumor cells [25]. In the resting state, NF- $\kappa$ B combines with its endogenous inhibitory factor $\mathrm{I} \kappa \mathrm{B}$ and forms a complex, so that it exists in the cytoplasm in an inactive state [26]. Studies have found that the upstream signaling factors in 


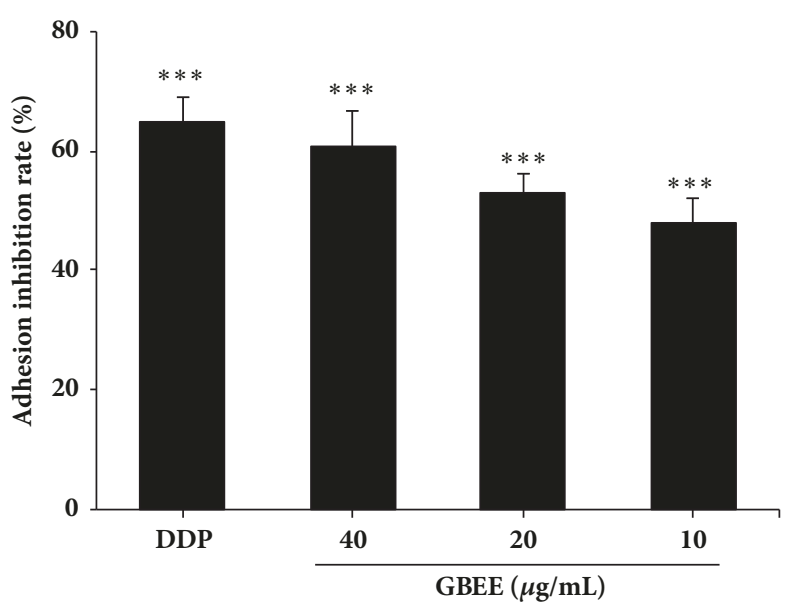

FIGURE 6: GBEE inhibited the adhesion of B16-F10 cells to HUVEC. The B16-F10 cells were treated with blank DMEM, DDP, and GBEE (10, 20 , and $40 \mu \mathrm{g} / \mathrm{mL}$ ) for $48 \mathrm{~h}$. Heterogeneous adhesion experiment was carried out. Data are shown as mean $\pm \operatorname{SD}(n=6) .{ }^{* * *} P<0.001$ versus control.

tumor cells can activate $\mathrm{I} \kappa \mathrm{B}$, making it dissociate from the complex. Then NF- $\kappa \mathrm{B}$ will be activated and enter the nucleus [27]. The promoter region of MMP-9 contains the binding site of NF- $\kappa$ B. So the activation of NF- $\kappa \mathrm{B}$ can increase the transcriptional activity of MMP-9, thereby the level of MMP9 is promoting $[28,29]$. As a result, inhibiting the activation of NF- $\kappa$ B can decrease the level of MMP-9 [30]. As one of the enzymes that specifically degrade ECM and BM, MMP9 is also closely related to the proliferation, migration, and heterogeneous adhesion of tumor cells. MMP-9 can promote tumor cell proliferation by releasing the cell-membranebound precursors of some growth factors [31,32]. MMP-9 can also promote the tumor cells to move forward by interacting with the integrins on the surface of the cells and modulating its function [33, 34]. Moreover, MMP-9 can enhance the heterogeneous adhesion of tumor cells via activating related cytokines [35] and then increasing the expression of intercellular adhesion molecule $[36,37]$. Therefore, inhibiting MMP9 expression can interfere with the tumor cell proliferation, migration, heterogeneous adhesion, and ECM and BM degradation. Studies have shown that the PI3K/Akt pathway is one of the major pathways that mediates cellular signaling. It participates in multiple processes or links in tumor metastasis [38]. When PI3K/Akt signaling pathway is activated in the tumor cells, the activated Akt activates $\mathrm{I} \kappa \mathrm{B}$ by phosphorylating $\mathrm{I} \kappa \mathrm{B}$ kinase. Then $\mathrm{NF}-\kappa \mathrm{B}$ is activated and enters the nucleus $[39,40]$. Scholars have confirmed that the PI3K/Akt signaling pathway can increase the level of MMP-9 through activating the NF- $\kappa \mathrm{B}$; therefore, the metastasis of tumor cells was enhanced [41]. These showed that PI3K/Akt/NF$\kappa \mathrm{B} / \mathrm{MMP}-9$ signaling pathway is involved in the regulation of tumor cell proliferation, migration, heterogeneous adhesion, and ECM and BM degradation. The in vitro results showed that at the mRNA and protein levels, GBEE $(10-40 \mu \mathrm{g} / \mathrm{mL})$ inhibited the expression of $\mathrm{p}-\mathrm{PI} 3 \mathrm{~K}, \mathrm{p}-\mathrm{Akt}$, NF- $\kappa$ B, and MMP-9 in a concentration-dependent manner in B16-F10 cells, while it had no significant effect on the PI3K and Akt. These results demonstrated that the inhibitory effect of GBEE on tumor cell proliferation, migration, heterogeneous adhesion, and ECM and BM degradation is related to the regulation of $\mathrm{PI} 3 \mathrm{~K} / \mathrm{Akt} / \mathrm{NF}-\kappa \mathrm{B} / \mathrm{MMP}-9$ signaling pathway.

\section{Conclusions}

Overall, the mechanisms of the antimetastasis effect of GBEE on B16-F10 melanoma metastasis involve regulating PI3K/Akt/NF- $\kappa \mathrm{B} / \mathrm{MMP}-9$ signaling pathway and further inhibiting tumor cell proliferation, migration, heterogeneous adhesion, and ECM and BM degradation.

\section{Data Availability}

The original experimental data used to support the findings of this study were included within the article.

\section{Conflicts of Interest}

The authors report no conflicts of interest in this work.

\section{Authors' Contributions}

Chenjie Cao and Ya Su contributed equally to this work.

\section{Acknowledgments}

This study was financially supported by the Medical HighTech Research Projects of Jiangsu Province (BG2007609) and Science and Technology Innovation Fund Projects of college students in Yangzhou University (x20170836). 


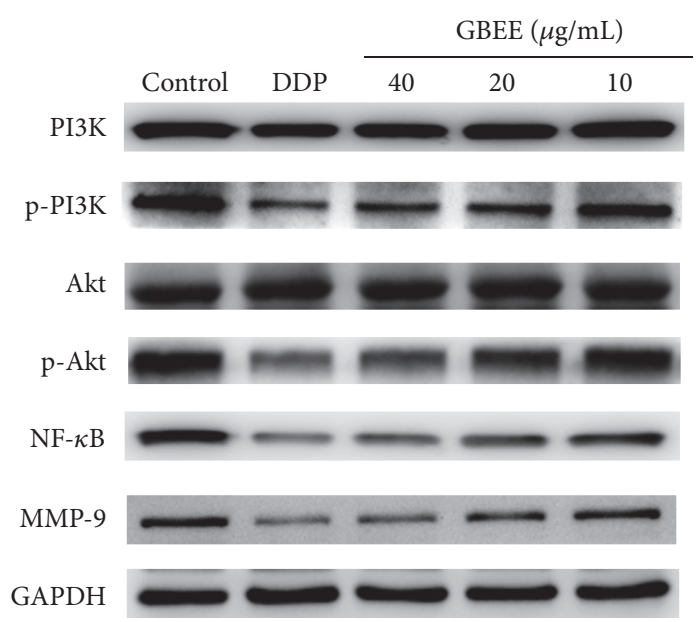

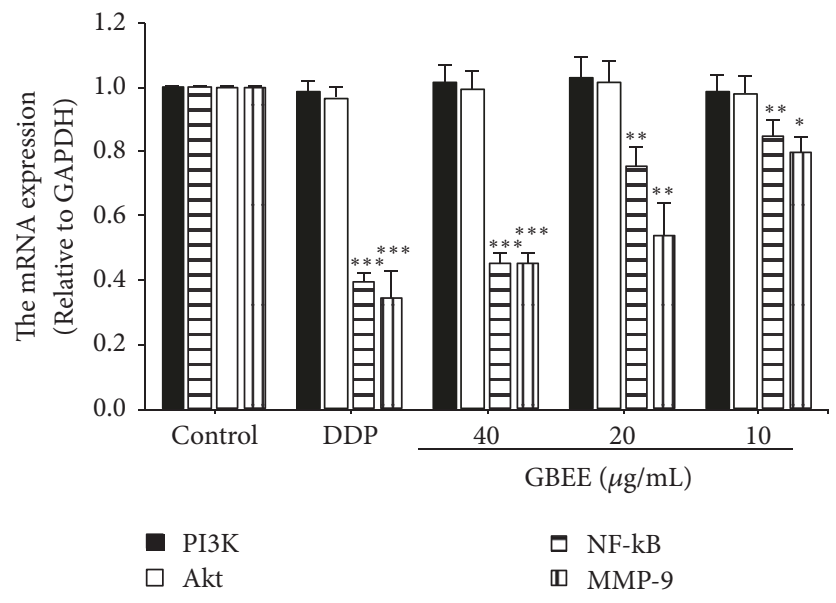

(a)

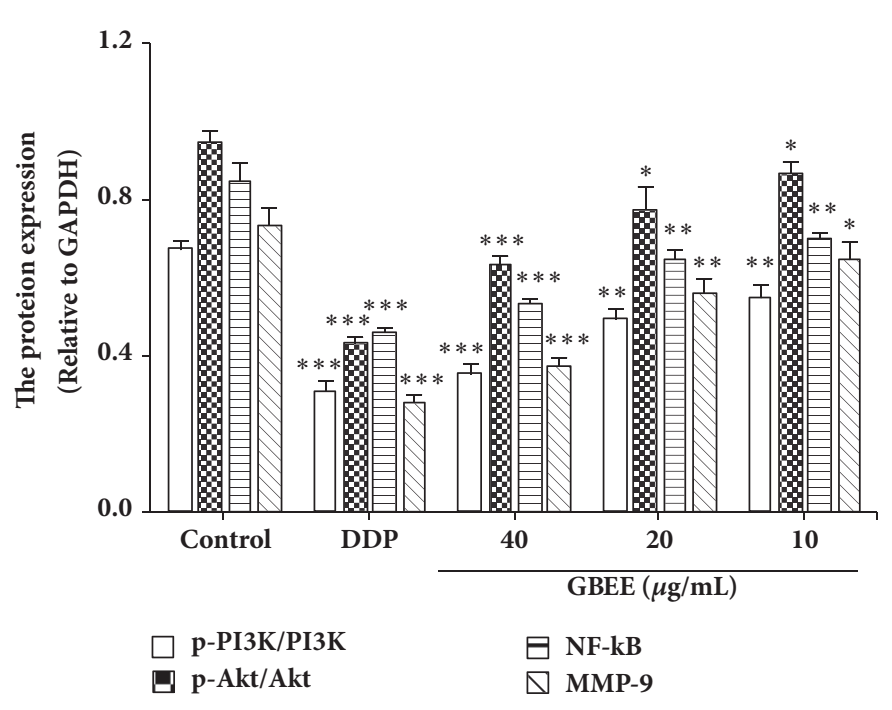

(b)

Figure 7: GBEE inhibited PI3K/Akt/NF- $\kappa$ B/MMP-9 signaling pathway in B16-F10 cells. The B16-F10 cells were treated with blank DMEM, DDP, and GBEE $(10,20,40 \mu \mathrm{g} / \mathrm{mL})$ for $48 \mathrm{~h}$. (a) The mRNA levels of NF- $\kappa \mathrm{B}$, MMP-9, PI3K, and Akt in cells were analyzed by qRT-PCR assay. (b) The protein levels of p-PI3K, PI3K, p-Akt, Akt, NF- $\kappa$ B, and MMP-9 were determined by Western Blot assay. Data are shown as mean \pm $\mathrm{SD}(\mathrm{n}=3) .{ }^{*} P<0.05,{ }^{* *} P<0.01$, and ${ }^{* * *} P<0.001$ versus control.

\section{References}

[1] W. Chen, Y. Lu, J. Wu, M. Gao, A. Wang, and B. Xu, "Betaelemene inhibits melanoma growth and metastasis via suppressing vascular endothelial growth factor-mediated angiogenesis," Cancer Chemotherapy and Pharmacology, vol. 67, no. 4, pp. 799-808, 2011.

[2] F. W. Shen, L. Ye, J. G. Liu, Y. L. Zhu, M. Tao, and X. P. Qian, "Progress in small-molecule targeted therapy for the treatment of melanoma," Chinese Journal of New Drugs, vol. 3, pp. 281-287, 2015.

[3] R. J. Davey, A. V. D. Westhuizen, and N. A. Bowden, "Metastatic melanoma treatment: Combining old and new therapies," Critical Review in Oncology/Hematology, vol. 98, pp. 242-253, 2015.

[4] R. B. Chen, B. Y. Ding, Z. Y. Wu, J. Q. Song, H. T. Bai, and N. Y. $\mathrm{Xu}$, "Molecular targeted therapeutic agents for anti-malignant melanoma," China Modern Medicine, vol. 23, no. 32, pp. 11-13, 2016.
[5] S. L. Yue, Q. F. Zhou, G. Y. Shi, T. J. Wang, X. L. Yue, and J. Wu, "Targeted therapy for Melanoma," Progress in Modern Biomedicine, vol. 16, no. 6, pp. 1172-1174, 2016.

[6] Y. Zhu and S. Bu, "Curcumin Induces Autophagy, Apoptosis, and Cell Cycle Arrest in Human Pancreatic Cancer Cells," Evidence-Based Complementary and Alternative Medicine, vol. 2017, Article ID 5787218, 13 pages, 2017.

[7] H. C. Shen, H. L. Wang, L. Wang et al., "Ethanol Extract of Root of Prunus persica Inhibited the Growth of Liver Cancer Cell HepG2 by Inducing Cell Cycle Arrest and Migration Suppression," Evidence-based Complementary and Alternative Medicine, vol. 2017, Article ID 8231936, 7 pages, 2017.

[8] N. B. Van Der Walt, Z. Zakeri, and M. J. Cronjé, “The induction of apoptosis in A375 malignant melanoma cells by Sutherlandia frutescens," Evidence-Based Complementary and Alternative Medicine, vol. 2016, Article ID 4921067, 14 pages, 2016. 
[9] C.-T. Chiu, S.-W. Hsuan, H.-H. Lin, C.-C. Hsu, F.-P. Chou, and J.-H. Chen, "Hibiscus sabdariffa Leaf polyphenolic extract induces human melanoma cell death, apoptosis, and autophagy," Journal of Food Science, vol. 80, no. 3, pp. H649-H658, 2015.

[10] T. S. Ye, "Renewed materia medica," in Fruit, vol. 5, Shanghai Qun Xue Press, Shanghai, China, 1919.

[11] A. H. Xu, H. S. Chen, Q. Wu, Q. Yang, and J. Li, "Preparation method of Ginkgo biloba exocarp extracts and its active part with anti-tumor and immune promoting activity," Chinese patent CN 201010251050.9, Yangzhou University, 2011.

[12] J. Wang, M. Yin, D. D. Han, L. L. Mao, and A. H. Xu, "Determination of heavy metal elements and Ginkgolic acid in Ginkgo biloba exocarp extracts," Modernization of Traditional Chinese Medicine and Materia Medica-WORLD SCIENCE AND TECHNOLOGY, vol. 18, no. 1, pp. 65-68, 2016.

[13] C. Cao, Y. Su, D. Han et al., "Ginkgo biloba exocarp extracts induces apoptosis in Lewis lung cancer cells involving MAPK signaling pathways," Journal of Ethnopharmacology, vol. 198, pp. 379-388, 2017.

[14] A. H. Xu, H. S. Chen, C. Zhu, X. W. Wang, and H. Q. Zhang, "The inhibitory effect of Ginkgo biloba exocarp polysaccharides (GBEP) on human cancer cell strains and its synergic effect in combination with adriamycin," Chinese Journal of New Drugs, vol. 9, no. 11, pp. 753-755, 2000.

[15] A. H. Xu, X. Q. Jia, H. S. Chen, Z. Y. Zhou, and Y. Q. Zhu, "Study on the inhibition of Hepatoma in mice and induction of apoptosis in Hepatoma cells with Ginkgo biloba exocarp polysaccharides (GBEP)," TraditionalChinese Drug Research Clinical Pharm, vol. 12, no. 5, pp. 340-341, 2001.

[16] A. H. Xu, L. Ren, Y. Y. Zheng, and H. S. Chen, "Regulation of Ginkgo biloba exocarp polysaccharides (GBEP) on immune response induced by cyclophosphamide in immunosuppressed mice," Chinese Journal of Pharmacology and Toxicology, vol. 22, no. 1, pp. 69-72, 2008.

[17] H. S. Chen, A. H. Xu, Y. Wang, Q. Wang, and X. L. Wang, "Effect of Ginkgo biloba exocarp polysaccharides (GBEP) on IL-2 activity and slL-2R in immunocompromised mice," Pharmacology and Clinics of Chinese Materia Medica, vol. 17, no. 4, pp. 17-19, 2001.

[18] H. S. Chen, F. Zhan, Y. F. Chu, F. Xu, A. H. Xu, and L. C. Jia, "Clinical study on treatment of patients with upper digestive tract malignant tumors of middle and late stage with Ginkgo biloba exocarp polysaccharides (GBEP) capsule preparation," Journal of Integrative Medicine, vol. 1, no. 3, pp. 189-191, 2003.

[19] F. Zhai and H. S. Chen, "Treatment of 84 cases of middle and late stage cancer with Ginkgo biloba exocarp polysaccharides (GBEP) preparation," Liaoning Journal of Traditional Chinese Medicine, vol. 29, no. 9, p. 564, 2002.

[20] B. Y. Hu, L. L. Mao, J. Wang, and A. H. Xu, "Qualitative and quantitative analysis of Ginkgo biloba exocarp extracts," Jorunal of Chinese Medicinal Materials, vol. 37, no. 8, pp. 1400-1403, 2014.

[21] R. G. Yi, X. Y. Xu, and S. R. Li, "Research progress on the mechanism of tumor invasion and metastasis," Journal of Chinese Practical Diagnosis and Therapy, vol. 28, no. 10, pp. 937939, 2014.

[22] C. Y. Li, Q. Wang, K. Shen, and G. X. Li, "Research progress on mechanisms of monomer ingredients of Chinese materia medica anti-tumor invasion and metastasis," Drug Evaluation Research, vol. 8, pp. 1168-1172, 2017.
[23] A. Alaseem, K. Alhazzani, P. Dondapati, S. Alobid, A. Bishayee, and A. Rathinavelu, "Matrix Metalloproteinases: A challenging paradigm of cancer management," Seminars in Cancer Biology, 2017.

[24] H. Zhang, C. Hao, Y. Wang et al., "Sohlh2 inhibits human ovarian cancer cell invasion and metastasis by transcriptional inactivation of MMP9," Molecular Carcinogenesis, vol. 55, no. 7, pp. 1127-1137, 2016.

[25] M. C. Sempere, V. R. Fanjul, I. S. Pérez, and R. Perona, "The role of the $\mathrm{NF} \kappa \mathrm{B}$ signalling pathway in cancer," Clinical and Translational Oncology, vol. 10, no. 3, pp. 143-147, 2008.

[26] J. C. Yu, M. Yu, and W. Mo, “The Role of NF- $\kappa$ B Signaling Pathway in Tumor Genesis and Inflammatory Reaction," Pharmaceutical Biotechnology, vol. 1, pp. 82-85, 2016.

[27] M. B. Qin, S. Q. Liu, A. M. Li et al., "NIK- and IKK $\beta$ binding protein promotes colon cancer metastasis by activating the classical NF- $\kappa \mathrm{B}$ pathway and MMPs," Tumour Biology the Journal of the International Society for Oncodevelopmental Biology \& Medicine, vol. 37, no. 5, pp. 5979-5990, 2015.

[28] J. H. Shi, W. Y. Wang, and Y. Li, "Expression of MMP-9, TIMP-1, and NF- $\kappa$ B in papillary thyroid carcinoma and its significance," Chinese Journal of Endocrinology and Metabolism, vol. 26, no. 2, pp. 129-131, 2010.

[29] M. S. Lee, D. Koh, G. S. Kim et al., "2-Hydroxy-3,4naphthochalcone ( $2 \mathrm{H}-\mathrm{NC})$ inhibits $\mathrm{TNF} \alpha$-induced tumor invasion through the downregulation of NF- $\kappa \mathrm{B}$-mediated MMP-9 gene expression," Bioorganic \& Medicinal Chemistry Letters, vol. 25, no. 1, pp. 128-132, 2015.

[30] L. Song, L. Liu, Z. Wu et al., "Knockdown of stomatin-like protein 2 (STOML2) reduces the invasive ability of glioma cells through inhibition of the NF- $\kappa \mathrm{B} / \mathrm{MMP}-9$ pathway," The Journal of Pathology, vol. 226, no. 3, pp. 534-543, 2012.

[31] M. Egeblad and Z. Werb, "New functions for the matrix metalloproteinases in cancer progression," Nature Reviews Cancer, vol. 2, no. 3, pp. 161-174, 2002.

[32] J. Song, B. H. Jiao, and J. T. Wang, "Effect of siRNA knockdown of MMP-9 gene expression on proliferation and invasion of human U251 glioma cells," Chinese Journal of Nervous and Mental Diseases, vol. 34, no. 5, pp. 299-302, 2008.

[33] W. G. Stetler-Stevenson and A. E. Yu, "Proteases in invasion: matrix metalloproteinases," Seminars in Cancer Biology, vol. 11, no. 2, pp. 143-152, 2001.

[34] M. Rolli, E. Fransvea, J. Pilch, A. Saven, and B. FeldingHabermann, "Activated integrin $\alpha \mathrm{v} \beta 3$ cooperates with metalloproteinase MMP-9 in regulating migration of metastatic breast cancer cells," Proceedings of the National Acadamy of Sciences of the United States of America, vol. 100, no. 16, pp. 9482-9487, 2003.

[35] N. Johansson, M. Ahonen, and V. M. Kähäri, "Matrix metalloproteinases in tumor invasion," Cellular \& Molecular Life Sciences Cmls, vol. 57, no. 1, pp. 5-15, 2000.

[36] J. Wang, W.-Y. Huang, Q.-S. Zheng, X.-N. Wang, and C.-Y. Li, "Effect of TNF- $\alpha$ on expression of ICAM-1 and VCAM-1 in HUVEC," Chinese Pharmacological Bulletin, vol. 29, no. 8, pp. 1179-1180, 2013.

[37] D. Hutchins and C. M. Steel, "Regulation of ICAM-1 (CD54) expression in human breast cancer cell lines by interleukin 6 and fibroblast-derived factors," International Journal of Cancer Journal International Du Cancer, vol. 58, no. 1, pp. 80-84, 2010.

[38] L. Guo and Q. Wang, "Correlation of PI3K/AkT/mTOR signal pathway to infiltration and metastasis of malignant tumor," Journal of Modern Oncology, vol. 17, no. 8, pp. 1585-1589, 2009. 
[39] Y. Gao, R. B. Gartenhaus, R. G. Lapidus et al., "Differential IKK/NF- $\kappa$ B Activity Is Mediated by TSC2 through mTORC1 in PTEN-Null prostate cancer and tuberous sclerosis complex tumor cells," Molecular Cancer Research, vol. 13, no. 12, pp. 16021614, 2015.

[40] M. Jeon, J. Han, S. J. Nam, J. E. Lee, and S. Kim, "STC-1 expression is upregulated through an Akt/NF- $\kappa \mathrm{B}$-dependent pathway in triple-negative breast cancer cells," Oncology Reports, vol. 36, no. 3, pp. 1717-1722, 2016.

[41] S. Y. Shin, C. G. Kim, Y. J. Jung, Y. Lim, and Y. H. Lee, “The UPR inducer DPP23 inhibits the metastatic potential of MDA-MB231 human breast cancer cells by targeting the Akt-IKK-NF- $\kappa$ BMMP-9 axis," Scientific Reports, vol. 6, 2016. 


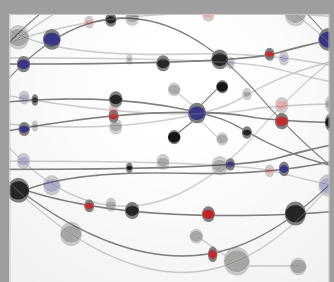

The Scientific World Journal
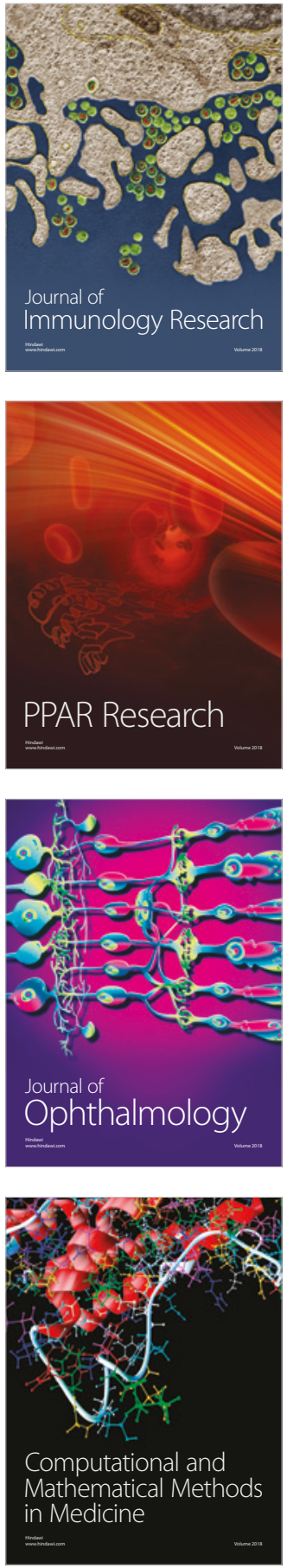

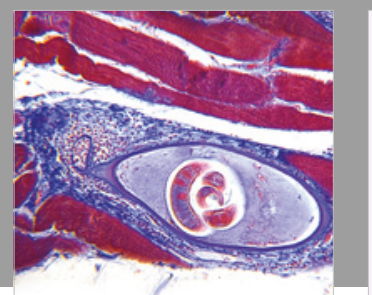

Gastroenterology Research and Practice

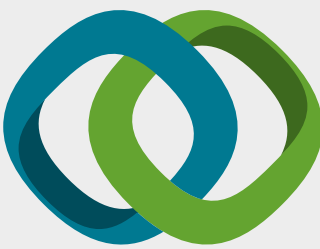

\section{Hindawi}

Submit your manuscripts at

www.hindawi.com
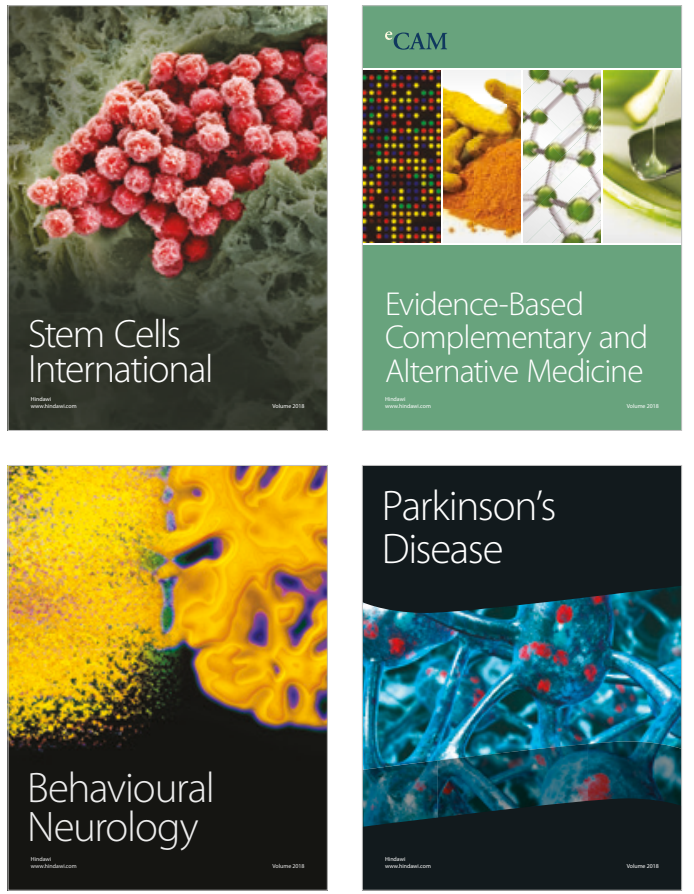

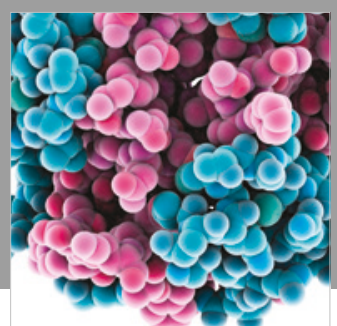

ournal of

Diabetes Research

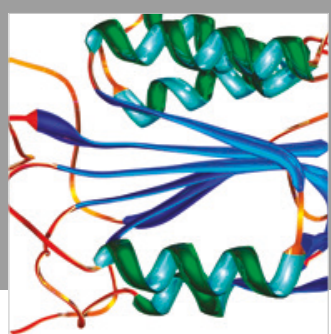

Disease Markers
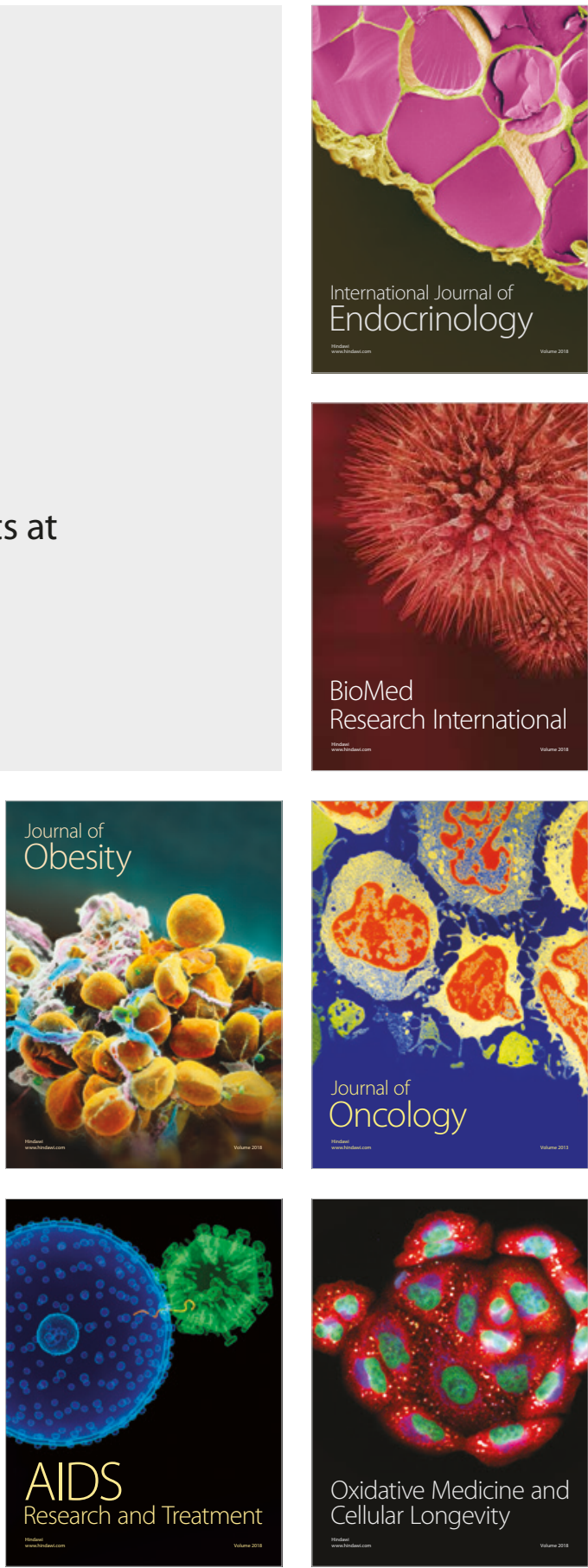